\title{
Rapid flow cytometry-based assay for the evaluation of $\gamma \delta$ T cell-mediated cytotoxicity
}

\author{
QILI JIN ${ }^{1,2}$, LINA JIANG ${ }^{1,3}$, QIAO CHEN $^{4}$, XIAOXIAO LI $^{4}$, YINYIN XU ${ }^{4}$, \\ XUEQIAN SUN ${ }^{4}$, ZIYUE ZHAO ${ }^{4}$ and $\mathrm{LI} \mathrm{WEI}^{1,5}$

\begin{abstract}
${ }^{1}$ Anhui Provincial Key Laboratory of Infection and Immunity, Bengbu Medical College, Bengbu, Anhui 233030; Departments of ${ }^{3}$ Physiology and Pathophysiology, ${ }^{4}$ Laboratory Medicine, and ${ }^{5}$ Microbiology and Parasitology, Bengbu Medical College, Bengbu, Anhui 233030, P.R. China
\end{abstract} \\ ${ }^{2}$ Department of Clinical Laboratory, The Second Affiliated Hospital of Bengbu Medical College, Bengbu, Anhui 233040;
}

Received March 28, 2017; Accepted October 24, 2017

DOI: $10.3892 / \mathrm{mmr} .2017 .8281$

\begin{abstract}
The effector function of natural killer, lymphokineactivated killer cells and $\mathrm{T}$ lymphocytes is commonly evaluated by radioactive chromium-release cytotoxicity assays. In addition to this indirect method, fluorescence assays have been described for the assessment of in vitro cell-mediated cytotoxicity. In the present study, target cells were stained with 5-(and-6)-carboxyfluorescein diacetate succinimidyl ester (CFSE), which is a stable integrated fluorescent probe that allows target and effector cells to be distinguished from one another. Staining of target THP-1 cells with $8 \mu \mathrm{M}$ CFSE revealed high and stable loading of fluorescence and no effect of the viability of cells. After $4 \mathrm{~h}$ of in vitro co-culture between $\gamma \delta \mathrm{T}$ cells and CFSE-labeled infected or uninfected THP-1 cells, staining with propidium iodide (PI) was performed to distinguish between vital and dead cells. During sample acquisition, target cells were gated on the CFSE positivity and examined for cell death based on the uptake of PI. CFSE and PI double positive cells were recognized as the dead target cells. The percentage of cytotoxicity in the CFSE-gated cell population was calculated by subtracting the value obtained for non-specific PI-positive target cells, which was measured in a control group that did not contain effector cells. The present study describes a simple and convenient assay that is based on the direct quantitative and qualitative analysis of cell damage at a single cell level utilizing a two-color flow cytometric assay. In conclusion, the flow cytometric-based assay described in the current study is a simple, sensitive and reliable tool to determine the cytolytic activity of $\gamma \delta \mathrm{T}$ lymphocytes against mycobacteria. Therefore, the present study may provide
\end{abstract}

Correspondence to: Dr Li Wei, Department of Microbiology and Parasitology, Bengbu Medical College, 2600 Dong Hai Road, Bengbu, Anhui 233030, P.R. China

E-mail: weili060903@126.com

Key words: flow cytometry, $\gamma \delta \mathrm{T}$ cells, cytotoxicity, Mycobacterium tuberculosis valuable information concerning the methods employed to investigate the function of $\gamma \delta \mathrm{T}$ cells and potentially other lymphocyte subsets.

\section{Introduction}

According to a 2014 report by the World Health Organization (WHO), one-third of the global population is infected with Mycobacterium tuberculosis (M.tb), the agent responsible for human tuberculosis. Furthermore, WHO estimates that there are $\sim 1.5$ million deaths worldwide from this disease annually and an increasing number of drug-resistant cases are reported each year (1). Tuberculosis remains a concerning global health issue, which is partially due to a limited understanding of the details underlying the host protective immune response to the infection.

Human $\gamma \delta$ T cells are a subset of T cells that express the $\gamma \delta$ $\mathrm{T}$ cell receptor (TCR) and are a unique lymphocyte population with a specific tissue distribution and antigen (Ag) recognition pathway $(2,3)$. Although these cells are thought to make up only a small proportion (3-10\%) of the circulating $\mathrm{CD}^{+} \mathrm{T}$ cells in peripheral blood, $\gamma \delta \mathrm{T}$ cells have essential roles in host defenses against invasive pathogens $(4,5)$. The involvement of $\gamma \delta \mathrm{T}$ cells in the host response to mycobacterial infections was described as early as 1989 (6). The expansion and activation of $\gamma \delta$ T cells was reported during M.tb invasion, which indicates the importance of $\gamma \delta \mathrm{T}$ cells in the control of infection (7). Consistent with this report, the suppression of $\gamma \delta \mathrm{T}$ cells by chronic tuberculosis infection leads to a poor outcome (8).

$\gamma \delta \mathrm{T}$ cells participate in early immunity against infection through multiple pathways, including the production of potent, soluble proinflammatory molecules (such as interferon- $\gamma$ and tumor necrosis factor- $\alpha$ ) and chemokines, rapid cytotoxicity or crosstalk with other cell types that are involved (such as natural killer cells, macrophages and dendritic cells) (9). $\gamma \delta \mathrm{T}$ cells exhibit different degrees of cytolytic activity in response to various types of pathogens, such as influenza viruses, which include human seasonal $\mathrm{H} 1 \mathrm{~N} 1$ and avian $\mathrm{H} 5 \mathrm{~N} 1$ and $\mathrm{H} 9 \mathrm{~N} 2$ viruses (10-12).. Wallace et al (13) reported that $\gamma \delta \mathrm{T}$ cells from patients infected with human immunodeficiency virus (HIV) exhibited antiviral potential through their cytolytic 
functions. Therefore, the direct killing of infected cells or invasive pathogens is the most important mechanism of $\gamma \delta \mathrm{T}$ cell-mediated immune responses to infection. The cytotoxicity of $\gamma \delta \mathrm{T}$ cells involves numerous pathways, including Fas-Fas ligand interactions and the secretion of perforin, granzyme B and granzyme $\mathrm{M}(14,15)$. Although defects in these cytotoxic mechanisms lead to the suppression of $\gamma \delta \mathrm{T}$ cell activity in various diseases, Poccia et al (16) revealed that stimulation with phosphoantigen enhances the function of $\gamma \delta$ T cells and may suppress HIV infection through cell-release antiviral factors, which may become a novel target for effective therapeutic strategies to control the infection.

Based on our understanding of $\gamma \delta$ T cell function and their importance in infectious disease, determining the number of $\gamma \delta \mathrm{T}$ cells is not sufficient and a suitable clinical assay for $\gamma \delta$ $\mathrm{T}$ cell activity is required. The traditional method for cytotoxicity assays involves radioisotope labelling of target cells with ${ }^{51} \mathrm{Cr}$, following which the $\gamma \delta \mathrm{T}$ cell-specific activity is determined by measuring ${ }^{51} \mathrm{Cr}$ release following co-culture of target cells with the effector $(\gamma \delta \mathrm{T})$ cells (17). This assay is commonly used despite it being associated with certain disadvantages, including low sensitivity and the use of hazardous radiation. Additionally, the method is operationally complex and time consuming. In recent years, several novel assays using flow cytometry have been developed to measure natural killer cytotoxicity without the use of radioactivity (18-19). The objective of the present study was to optimize a rapid flow cytometry-based assay to assess the cytolytic activity of $\gamma \delta \mathrm{T}$ cells following M.tb infection.

\section{Materials and methods}

M.tb culture and infection. In the present study, M.tb (H37Ra) (cat no. 93020-5; General Microbiological Culture Collection Center, Beijing, China) was cultured in Sauton's medium supplemented with $0.05 \%$ Tween-80 (Hefei Real Biotechnology Co., Ltd., Hefei, China) for 4-6 weeks to late log phase, and the mycobacterial cells were harvested and washed three times with normal saline. Prior to infection, bacteria were incubated with RPMI-1640 (Gibco; Thermo Fisher Scientific, Inc., Waltham, MA, USA) medium and rocked for $30 \mathrm{~min}$ at $37^{\circ} \mathrm{C}$, clumps were disrupted by multiple passages through a 25-gauge needle, as demonstrated in Fig. 1A. Subsequently, bacteria were resuspended in a physiologic solution at $3 \times 10^{8}$ colony-forming units (CFU)/ml.

To evaluate the phagocytosis of $M . t b$ by THP-1 cells, bacteria were labeled with fluorescein isothiocyanate (FITC) as follows: $3 \times 10^{8} \mathrm{CFU} / \mathrm{ml}$ M.tb were incubated with $0,20,50$ and $100 \mu \mathrm{g}$ FITC per $\mathrm{ml}$ at $37^{\circ} \mathrm{C}$ for $2 \mathrm{~h}$. Subsequently, labeled bacteria were washed three times with PBS $(0.05 \%$ Tween- 80$)$ to remove unbound FITC. Thereafter, cells were resuspended

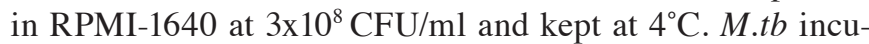
bated with $0 \mu \mathrm{g} / \mathrm{ml}$ was used as blank control. During data analysis, values of each group (20, 50 and $100 \mu \mathrm{g} / \mathrm{ml})$ were obtained by subtracting this background.

Differentiation of THP-1 cells. The THP-1 monocytic leukemia cell line (Shanghai Bogoo Biotechnology Co. Ltd., Shanghai, China) was cultured at $37^{\circ} \mathrm{C}$ with $5 \% \mathrm{CO}_{2}$ and $95 \%$ humidity in RPMI-1640 medium supplemented with $10 \%$ fetal bovine serum (FBS; Gibco; Thermo Fisher Scientific, Inc.), $2 \mathrm{mM}$ L-glutamine, $100 \mathrm{U} / \mathrm{ml}$ streptomycin and penicillin. Cells were seeded at a density of $105 / \mathrm{cm}^{2}$ and allowed to adhere and differentiate. Monocytic differentiation was induced with phorbol 12-myristate 13 -acetate (PMA) at a final concentration of $40 \mathrm{ng} / \mathrm{ml}$ for $24 \mathrm{~h}$ at $37^{\circ} \mathrm{C}$ in a humidified atmosphere with $5 \% \mathrm{CO}_{2}$. To evaluate the expression of $\mathrm{CD} 14$ on THP-1 cells, cells were harvested and incubated with FITC anti-human CD14 monoclonal antibody (eBioscience; Thermo Fisher Scientific, Inc.) on ice for $30 \mathrm{~min}$ and then washed twice with PBS. Cells were subsequently analyzed by flow cytometry and CellQuest ${ }^{\mathrm{TM}}$ software version 3.3 (BD Biosciences, Franklin Lakes, NJ, USA) and WinMDI 2.8 (J. Trotter, The Scripps Research Institute, La Jolla, CA, USA).

Phagocytosis of M.tb by THP-1 cells. Quantitative analysis of phagocytosis was determined by using the fluorescence quenching technique. Briefly, FITC-labeled bacterial suspensions were added to $3 \times 10^{5}$ PMA-differentiated THP-1 cells at different multiplicity of infections (MOIs; 1:1-100:1) and incubated for 1 and $2 \mathrm{~h}$, or incubated for different durations (1-6 h) at an MOI of $10: 1$, at $37^{\circ} \mathrm{C}$. Those in blank control group were treated with no bacteria (MOI 0) or no incubation duration $(0 \mathrm{~h})$. Subsequently, cultures were washed and resuspended in $0.125 \%$ trypan blue ( $\mathrm{pH} 4.4$ ) for 3 min to quench the fluorescence of non-ingested, but membrane-associated bacteria. The percentage of cells that exhibited positive FITC expression was analyzed as the phagocytosis rate by subtracting the value of control group.

Preparation of M.tb heat-treated Ag. (M.tb-HAg). M.tb-HAg were prepared according to the methods described in a previous report (20). Briefly, M.tb were cultured, collected, washed, resuspended in double volumes of ultra-pure water and heated at $120^{\circ} \mathrm{C}$ for $30 \mathrm{~min}$. The supernatants from heat-treated M.tb cells were harvested and concentrated to $1 \mathrm{mg} / \mathrm{ml}$ prior to use for stimulating $\gamma \delta \mathrm{T}$ cells.

Expansion of effective $\gamma \delta T$ cells. Peripheral blood mononuclear cells were isolated from the freshly heparinized venous blood of healthy volunteers by density gradient centrifugation using Ficoll-Hypaque (21). Ethical approval was obtained from the ethical committee of Bengbu Medical College, Bengbu, China. Each healthy donor signed informed consent according to institutional guidelines. Written informed consent was obtained from each healthy donor according to federal and institutional guidelines. Cells were maintained at $1.5 \times 10^{6}$ cells $/ \mathrm{ml}$, with $1 \mathrm{ml} /$ well in 24 -well cell culture plates in complete RPMI-1640 medium supplemented with $10 \%$ (v/v) FBS and $50 \mu \mathrm{g} / \mathrm{ml}$ gentamycin (Beijing Biodee Biotechnology Co., Ltd., Beijing, China). These cells were cultured at $37^{\circ} \mathrm{C}$ in $5 \% \mathrm{CO}_{2}$ in the presence of $50 \mathrm{U} / \mathrm{ml}$ recombinant human interleukin (IL)-2 (rhIL-2; Biomics Biotechnologies Co., Ltd., Nantong, China) and $5 \mu \mathrm{g} / \mathrm{ml} M . t b-\mathrm{HAg}$ for 7-10 days and fed with fresh medium and cytokines every 3-4 days. The M.tb-HAg and rhIL-2-stimulated T cells were described as $M . t b$-HAg activated T cells, which were stained for surface markers with FITC anti-human CD3 and phycoerythrin (PE) anti-human TCR $\gamma \delta$. Both fluorochrome-conjugated monoclonal antibodies were purchased from eBioscience; Thermo 
A

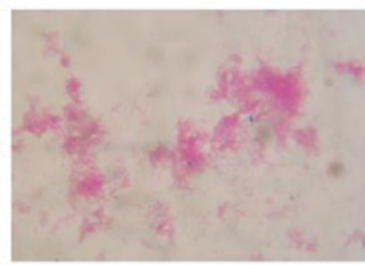

B

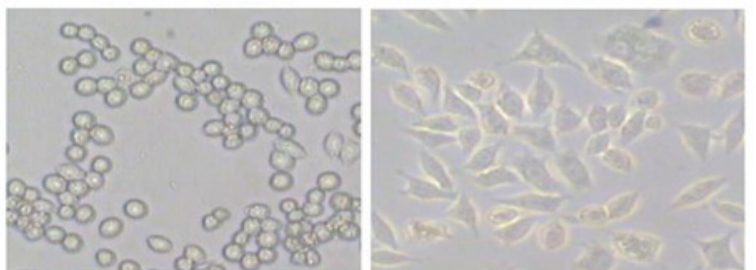

C

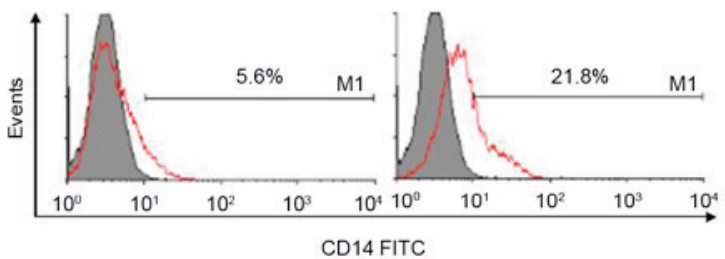

Figure 1. Alteration of morphology and phenotype in PMA-differentiated THP-1 cells. (A) Aggregate (left) and dispersed (right) M.tb stained with routine acid-fast staining (magnification, x1,000). (B) Morphology of THP-1 (left) and PMA- differentiated THP-1 (right) cells (magnification, $\mathrm{x} 400$ ). (C) Phenotype of THP-1 cells. THP-1 (left) and PMA-differentiated THP-1 (right) cells were cultured and stained with FITC anti-human CD14 antibody (red) or an isotype control antibody (gray) and examined by flow cytometry. The results are representative of three independent experiments that gave similar results. PMA, phorbol 12-myristate 13 -acetate; M.tb, Mycobacterium tuberculosis; FITC, fluorescein isothiocyanate.

Fisher Scientific, Inc. $\gamma \delta$ T cells account for $\sim 70-85 \%$ of the total M.tb-HAg activated T cells, which were used as effective $\gamma \delta \mathrm{T}$ cells. Effector cells were adjusted to a final concentration of $1-2 \times 10^{6}$ cells $/ \mathrm{ml}$.

Infection of THP-1 cells. For infection of cells, $1 \times 10^{6}$ THP-1 or PMA-differentiated THP-1 cells were washed three times and replenished with culture medium without antibiotics and infected with M.tb at an MOI of 50 bacteria per cell. Bacteria were centrifuged onto THP-1 or differentiated THP-1 cells at $400 \mathrm{x} \mathrm{g}$ for $5 \mathrm{~min}$ at $4^{\circ} \mathrm{C}$. After a period of $2 \mathrm{~h}$ at $37^{\circ} \mathrm{C}$, non-ingested bacteria were removed by extensive washing with PBS and cells were collected and used as targets in cytotoxicity experiments. Meanwhile, Ziehl-Nielson acid-fast staining and laser scanning confocal microscopy (LSCM) was used to confirm the presence of intracellular bacteria. THP-1 or PMA-differentiated THP-1 cells $\left(1 \times 10^{6}\right)$ were seeded on coverslips and co-cultured with M.tb (for Ziehl-Nielson acid-fast staining) or FITC-labeled $M . t b$ (for LSCM) at an MOI of 50:1 and incubated for $2 \mathrm{~h}$ at $37^{\circ} \mathrm{C}$. Non-ingested bacteria were gently removed in warm PBS containing $0.5 \%$ bovine serum albumin (BSA) (Hefei Real Biotechnology Co., Ltd.). For analysis by confocal microscopy, cells on glass coverslips were fixed in $2 \%$ formaldehyde for $20 \mathrm{~min}$ on ice, then washed with PBS and blocked with 5\% BSA for 20 min at room temperature. Subsequently, the samples were incubated with PE anti-human Toll-like receptor-2 (eBioscience; Thermo Fisher Scientific, Inc.) for $30 \mathrm{~min}$ at room temperature, then rinsed gently in distilled water for $\sim 1$ min and mounted on microscopic slides. Images were captured using a laser confocal microscope (C1-Digital Eclipse, Nikon, Tokyo, Japan).

Cytotoxicity assay. To confirm the cell viability prior to cytotoxicity testing, Fluorescein diacetate (FDA) was used as a vital stain to assay membrane integrity (cell viability). $1 \times 10^{5}$ cells ( $\gamma \delta$ T cells, THP-1 cells or THP-1 cells infected with $M t . b$ ) were incubated at room temperature for $5 \mathrm{~min}$ in the presence of $50 \mathrm{ng} / \mathrm{ml}$ FDA, followed by analysis by flow cytometry. The cytotoxicity assay was performed when cell viability was $>85 \%$. Target THP-1 cells were labeled with carboxyfluorescein diacetate succinimidyl ester (CFSE; Invitrogen; Thermo Fisher Scientific, Inc.) as follows: CFSE (2, 4 and $8 \mu \mathrm{mol} / \mathrm{l})$ was added to the target cell suspension $\left(1 \times 10^{6} / \mathrm{ml}\right)$ at $37^{\circ} \mathrm{C}$ in $5 \% \mathrm{CO}_{2}$ for $10 \mathrm{~min}$. Following labeling, the cells were washed and analyzed in a flow cytometer. CFSE-labeled target cells were resuspended in RPMI-1640 to a final concentration of $1 \times 10^{5} / \mathrm{ml}$ for further investigation.

The cytotoxic function of $\gamma \delta$ T cells was evaluated by adding CFSE-labeled infected or uninfected THP-1 cells to yield effector:target (E:T) ratios of 20:1, 10:1, 5:1 and 1:1. Control tubes were also assayed to determine the spontaneous cell death. Tubes were gently mixed, centrifuged at $120 \mathrm{x} \mathrm{g}$ for $2 \mathrm{~min}$ at $4^{\circ} \mathrm{C}$ and incubated at $37^{\circ} \mathrm{C}$ in $5 \% \mathrm{CO}_{2}$. After $4 \mathrm{~h}$ of co-culture, cells were stained with $4 \mu \mathrm{l}$ propidium iodide (PI; $100 \mu \mathrm{g} / \mathrm{ml}$ ) and were placed on ice for $5 \mathrm{~min}$. The fluorescence intensity of cultured cells was measured by flow cytometry. During sample acquisition, a 'target cell gate' was set on the CFSE-positive cell population using a FL1-histogram, and 2,000 target cells were collected. For data analysis, the CFSE-positive target cells were examined for cell death by uptake of PI. CFSE and PI double positive cells were considered to be dead target cells. The percentage of cytotoxic activity was subsequently calculated using the following equation:

$$
\text { Cytotoxicity }(\%)=\frac{\text { Target cell deaths }- \text { spontaneous deaths }}{100-\text { spontaneous deaths }} \times 10 \mathrm{C}
$$

The cytotoxicity of $\gamma \delta \mathrm{T}$ cells against THP-1 cells was assessed also by measuring cytosolic lactate dehydrogenase $(\mathrm{LDH})$ release into culture supernatants using a $\mathrm{LDH}$ cytotoxicity assay kit (Hefei Bomei Biotechnology Co., Ltd., Hefei, China).

Statistical analysis. Data obtained from independent experiments are presented as the mean \pm standard deviation. Statistical analysis was performed using one-way analysis of variance and the Student-Newman-Keuls test. Data from experiments in Fig. 5 were analyzed using Student's t-test, and the correlation between the cytotoxic activity obtained by flow cytometry-based and LDH cytotoxicity assays was estimated by the nonparametric Spearman's Rank correlation test. $\mathrm{P}<0.05$ was considered to indicate a statistically significant difference. The statistical software package SPSS 15.0 (SPSS, Inc., Chicago, IL, USA) was used for all the data analysis.

\section{Results}

Alterations in the morphology and phenotype of PMA-differentiated THP-1 cells. As demonstrated in Fig. 1B, 

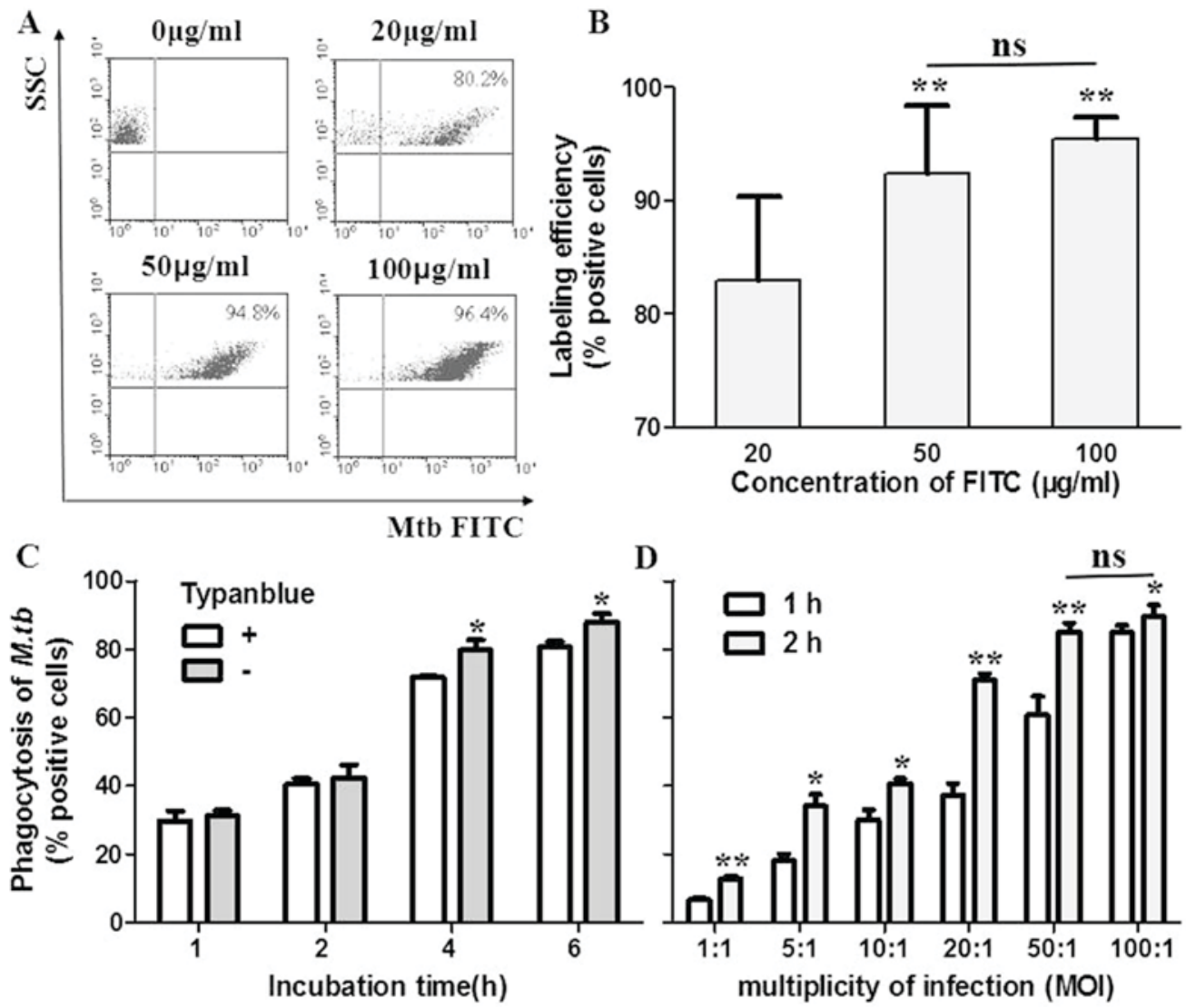

Figure 2. Phagocytosis of FITC-labeled M.tb by THP-1 cells. (A) Representative FACS dot plots demonstrate labeling efficiency at different concentrations of FITC. The numbers represent the percentage of FITC positive cells. (B) Mean labeling efficiency at different FITC concentrations in four independent experiments. ${ }^{* * *} \mathrm{P}<0.01 \mathrm{vs} .20 \mu \mathrm{g} / \mathrm{ml}$ FITC. (C) Effect of trypan blue on phagocytic rate. PMA-differentiated THP-1 cells were exposed to FITC-labeled $M$.t $t b$ at the ratio of 10:1 for 1-6 h. Following incubation, surface fluorescence emitted by non-internalized bacteria was quenched by exposure to trypan blue. ${ }^{*} \mathrm{P}<0.05$ vs. trypan blue-quenching group at same time-point. (D) PMA-differentiated cells were incubated with increasing concentrations of $M . t b$ for 1 or $2 \mathrm{~h}$. The percentage of cells phagocytosing M.tb was measured by FACS analysis. The results are representative of two independent experiments. "P $<0.05$ and ${ }^{* *} \mathrm{P}<0.01$ vs. $1 \mathrm{~h}$ at same MOI. FITC, fluorescein isothiocyanate; M.tb, Mycobacterium tuberculosis; FACS, fluorescence-activated cell sorting; PMA, phorbol 12-myristate 13-acetate; MOI, multiplicity of infection.

the shape of untreated THP-1 cells was round and cells did not adhere to the cell culture plate surface (left). In the presence of the common macrophage differentiation factor PMA for $24 \mathrm{~h}$, the cells became flat and amoeboid in shape, and adhered to the bottom of the plate (Fig. 1B, right). Cell cultures treated with PMA (Fig. 1B, right) consisted of bigger cells at a lower density compared with the cultures that were not treated with PMA (Fig. 1B, left).

Subsequently, the present study evaluated whether PMA was able to induce the expression of CD14, which is considered to be a potential receptor for M.tb. Flow cytometry analysis revealed that CD14 was upregulated with macrophage differentiation (Fig. 1C). Upon treatment with PMA, a substantial increase in the proportion of $\mathrm{CD}^{+} 4^{+}$cells $(21.8 \%$; Fig. 1C, right) was observed compared with untreated THP-1 cells (5.6\%; Fig. 1C, left; $\mathrm{P}<0.05$ ).

Phagocytosis of M.tb by THP-1 cells. Flow cytometry and FITC-labeled bacteria were used to measure the phagocytosis of M.tb by THP-1 cells. M.tb labeled with FITC at different concentrations were easily visualized by fluorescence microscopy, and no loss of viability was observed. The labeling efficiency of $M . t b$ was determined by flow cytometry and was increased with increasing FITC concentrations. Of the various
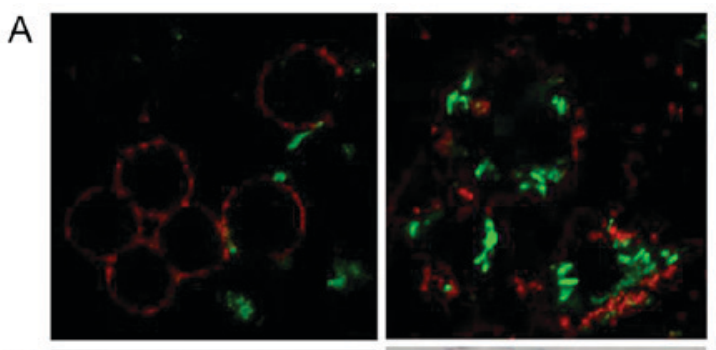

B

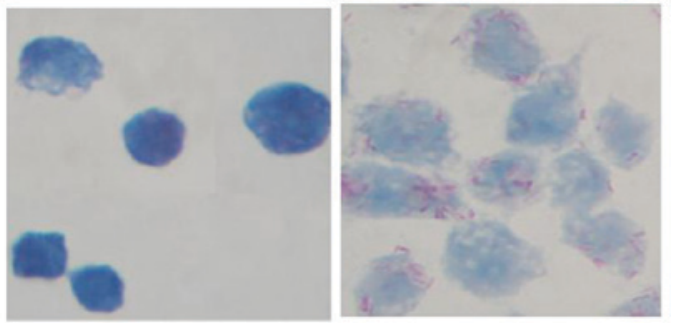

Figure 3. Use of microscopy to confirm the presence of intracellular bacteria following phagocytosis. (A) Fluorescence micrographs of THP-1 (left) and PMA-differentiated THP-1 (right) cells with phagocytosed fluorescein isothiocyanate-labeled M.tb and toll-like receptor 2-phycoerythrin antibody staining. Intracellular bacteria fluoresce green while the cell surface remains red (magnification, x1,000). (B) Light micrograph of THP-1 (left) and PMA-differentiated THP-1 (right) cells with phagocytosed $M . t b$ stained with routine acid-fast staining (magnification, x1,000). PMA, phorbol 12-myristate 13-acetate; M.tb, Mycobacterium tuberculosis. 
A

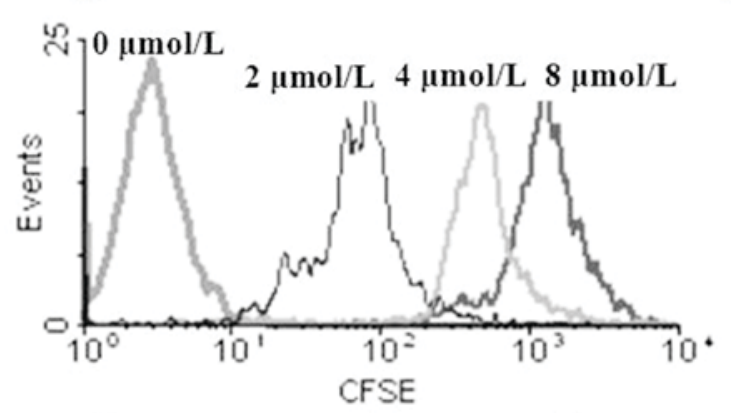

C

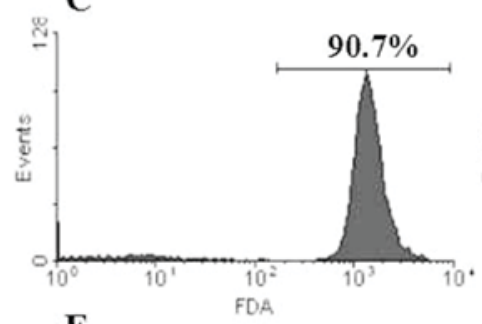

$\mathbf{F}$

D

B

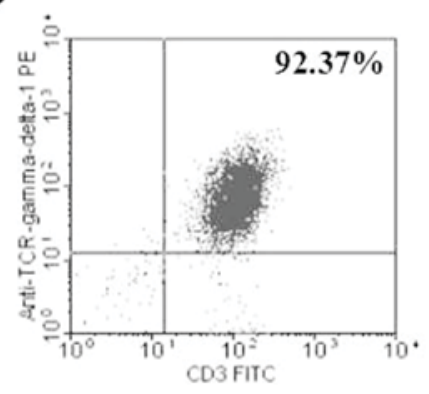

$\mathbf{E}$
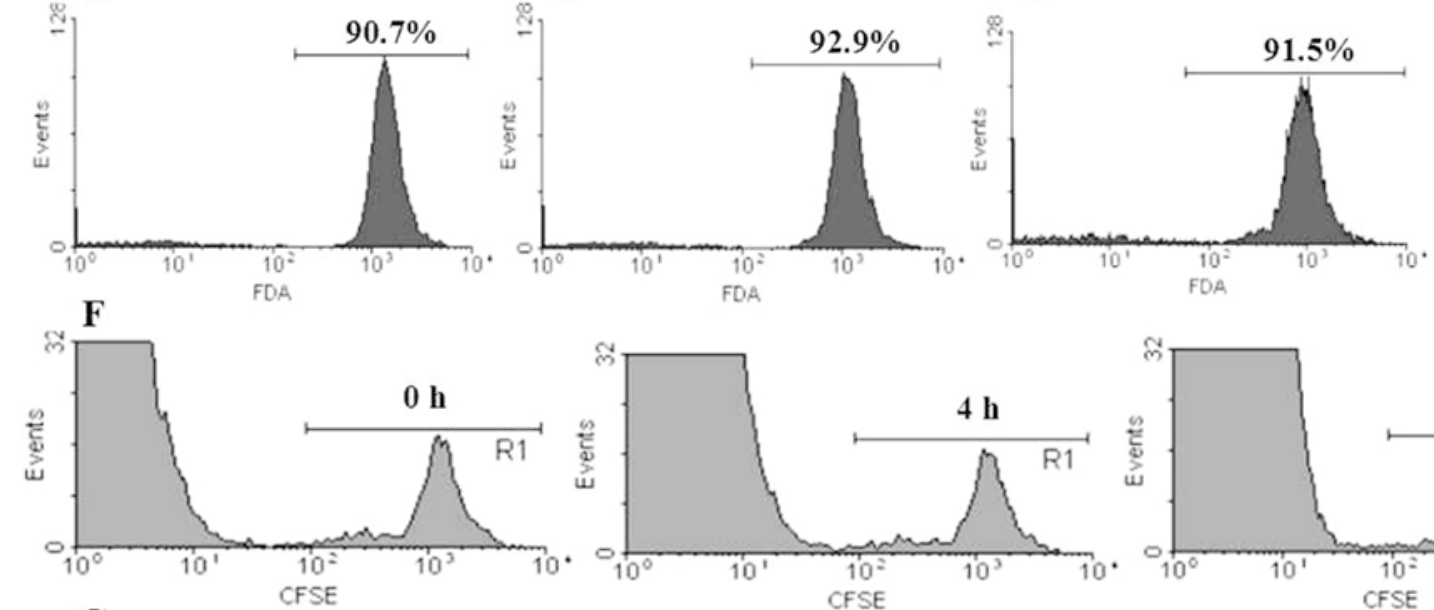

G

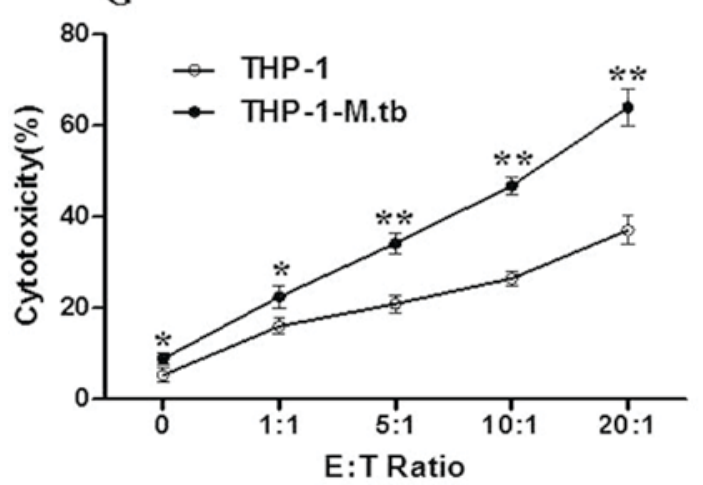

H

THP-1-M.tb
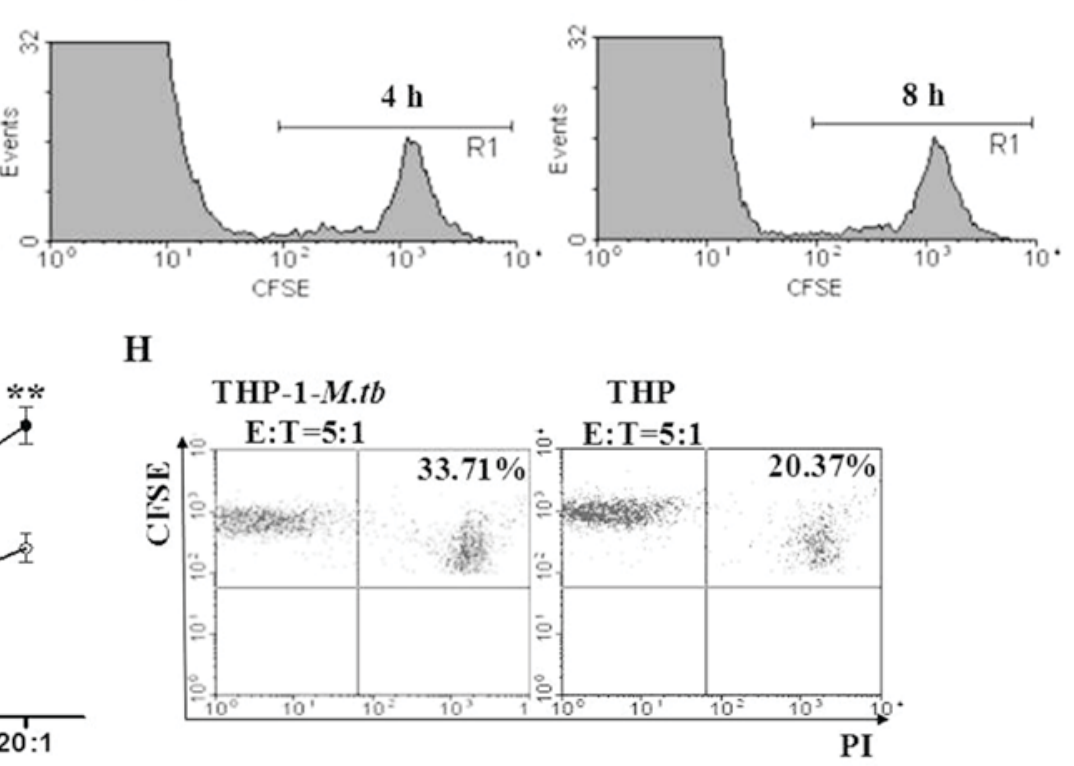

Figure 4. Flow cytometric analysis of $\gamma \delta \mathrm{T}$ cell cytotoxicity assay. (A) Histogram overlay demonstrates flow cytometric analysis of unlabeled target cells and target cells immediately after CFSE labeling. (B) Representative flow cytometry panel demonstrates the phenotype of recombinant human interleukin-2- and $M . t b$ heat-treated antigen-expanded T cells in which $\gamma \delta \mathrm{T}$ cells account for $\sim 92.35 \%$ of total cells. Histogram profiles of (C) $\gamma \delta \mathrm{T}$ cells (effectors), (D) THP-1 cells and (E) M.tb-infected THP-1 cells (targets) treated with FDA. Samples with $50 \mathrm{ng} / \mathrm{ml}$ FDA were incubated at room temperature for 5 min prior to analysis by flow cytometry to confirm the cell viability. (F) Histogram indicates the level of target cell division, as assessed by examining differences in CFSE fluorescence between cells immediately after labeling and at 4 and $8 \mathrm{~h}$ after labeling with CFSE. (G) Evaluation of $\gamma \delta \mathrm{T}$ cell cytotoxicity at different E:T ratios by the flow cytometry-based assay. Data are presented as the mean cytotoxicity value \pm standard deviation from one representative experiment of four independent experiments. ${ }^{*} \mathrm{P}<0.05$ and ${ }^{* *} \mathrm{P}<0.01$ vs. THP-1 cells at same E:T ratio. $(\mathrm{H})$ Representative fluorescence-activated cell sorting dot plot represents $\gamma \delta \mathrm{T}$ cell activity at an E:T ratio of 5:1 and dead target cells appear in the upper right quadrant. CFSE, 5-(and-6)-carboxyfluorescein diacetate succinimidyl ester; M.tb, Mycobacterium tuberculosis; E:T, effector:target; TCR, T cell receptor; PE, phycoerythrin; FITC, fluorescein isothiocyanate; PI, propidium iodide; FDA, fluorescein diacetate.

FITC concentrations employed, the maximum proportion of FITC positive cells was obtained using $50 \mu \mathrm{g} / \mathrm{ml}(92 \%)$ and $100 \mu \mathrm{g} / \mathrm{ml}(95 \%)$ FITC (Fig. 2A and B). No significant difference between the labeling efficiency at the concentrations of 50 and $100 \mu \mathrm{g} / \mathrm{ml}$ was observed. Therefore, bacteria were labeled with $50 \mu \mathrm{g} / \mathrm{ml}$ FITC for further experiments.

As demonstrated in Fig. 2C and D, THP-1 macrophages were exposed to bacteria at an MOI of 10:1 for different durations (1, 2, 4 and 6 h; Fig. 2C) or a range of bacterial concentrations
(MOI 1:1-100:1) for 1 and $2 \mathrm{~h}$ (Fig. 2D). The maximal loading of THP-1 cells with bacteria was obtained at the ratio of 100:1 at $2 \mathrm{~h}$; however, a ratio of 50:1 at $2 \mathrm{~h}$ was chosen as this MOI was associated with less cytotoxicity (85.20土2.59\%; Fig. 2D) or $10: 1$ for $6 \mathrm{~h}(80.90 \pm 1.47 \%)$. Following quenching of surface FITC fluorescence with trypan blue, the frequency of positivity decreased by $1 \%$ in the $1 \mathrm{~h}$ treatment group $(\mathrm{P}>0.05)$ and $7 \%$ in the $6 \mathrm{~h}$ treatment group $(\mathrm{P}<0.05$; Fig. $2 \mathrm{C})$. Routine acid-fast staining and LSCM confirmed the presence of intracellular 


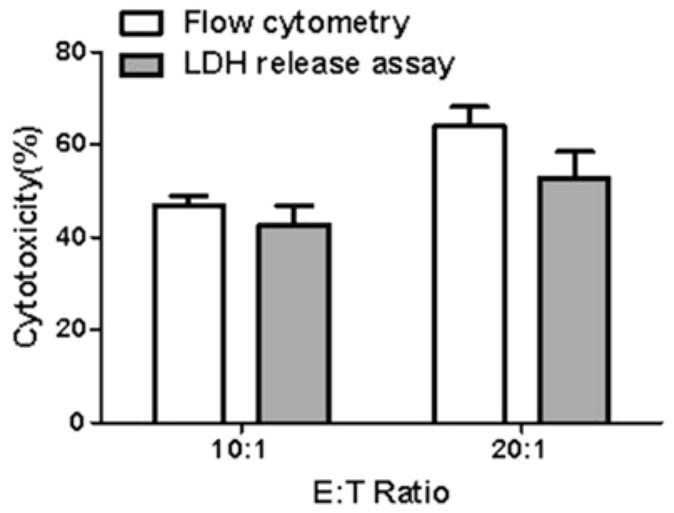

Figure 5. Comparison of $\gamma \delta \mathrm{T}$ cell cytotoxicity as assessed by flow cytometry-based and LDH release assays. The values for $\gamma \delta \mathrm{T}$ cell cytotoxicity obtained at various E:T ratios using flow cytometry and LDH release assays were compared. The mean of triplicate results is presented for E:T ratios of 10:1 and 20:1. LDH, lactate dehydrogenase; E:T, effector:target.

bacteria. Representative photomicrographs of infected cells with $M . t b$ are presented in Fig. 3.

Optimization of target cell labeling. For THP-1 cell (target cells) staining, three different concentrations $(2,4$ and $8 \mu \mathrm{M})$ of CFSE were employed and compared. Labeling with these concentrations of CFSE all allowed homogenous staining of $>90 \%$ of THP-1 cells. As the fluorescence intensity of CFSE per cell is naturally reduced upon cell division, an optimal separation between stained and unstained cells was observed at the concentration of $8 \mu \mathrm{M}$ CFSE (Fig. 4A).

Detection of $\gamma \delta T$ cell cytotoxicity. Effective $\gamma \delta$ T cells were collected from peripheral blood and the purity (CD3-TCR $\left.\gamma \delta^{+}\right)$ was $>90 \%$ on day 10 after incubation (Fig. 4B). Prior to using in cytotoxicity tests, cell labeling with FDA confirmed that cell viability was $>85 \%$ for $\gamma \delta$ T cells, THP-1 cells and THP-1 cells infected with $M . t b$ (Fig. 4C-E, respectively).

The performance of $\gamma \delta$ T cells in the cytotoxic assay was determined by adding CFSE-labeled infected or uninfected THP-1 cells at different E:T ratios. The loss of intensity was investigated by comparing freshly stained target cells with target cells that were stained and incubated for different durations, and no decrease in fluorescence intensity was observed up to $8 \mathrm{~h}$ of incubation (Fig. 4F). When $\gamma \delta \mathrm{T}$ cells were co-cultured with target cells for $4 \mathrm{~h}$ at ratios between 1:1 and 20:1, the cytotoxicities of $\gamma \delta \mathrm{T}$ cells against targets increased from $16.05 \pm 1.74 \%$ to $64.06 \pm 4.07 \%$ (Fig. $4 \mathrm{G}$ ). As demonstrated in Fig. 4G, the resulting cytotoxic activities increased with increasing E:T ratios, and, when infected THP- 1 cells were used as targets, the maximum $\gamma \delta \mathrm{T}$ cell cytotoxicity reached $64.06 \pm 4.07 \%$. Comparing between the assays that employed infected and uninfected THP-1 cells, the cytotoxic activities of $\gamma \delta \mathrm{T}$ cells against infected THP-1 cells were significantly higher compared with against uninfected THP-1 cells at each E:T ratio $(\mathrm{P}<0.05)$. Fig. 4H illustrated that samples were analyzed by 2 -color flow cytometry with CFSE gating to determine the cytotoxic activities at an E:T ratio of 5:1. CFSE and PI double positive cells (the upper right quadrant) were considered to be dead target cells.
The flow cytometry-based cytotoxicity assay was compared with the LDH cytotoxicity assay, which were run in parallel. All results obtained at E:T ratios 10:1 and 20:1 are presented in Fig. 5. The resulting cytotoxic activity was similar in both assays. In the flow cytometry-based cytotoxicity assay, the mean cell lysis at 10:1 and 20:1 ratios was $47.74 \pm 2.94 \%$ and $64.07 \pm 5.35 \%$, respectively, while the LDH cytotoxicity assay detected cell lysis with means of $42.59 \pm 5.32 \%$ and $52.78 \pm 6.39 \%$, respectively. The results of the two assays were significantly correlated $(\mathrm{r}=0.886$; $\mathrm{P}<0.05)$. The responses obtained at ratios 10:1 were, in general, lower compared with those at 20:1, in the flow cytometry-based cytotoxicity assay (1.3-fold) and the LDH cytotoxicity assay (1.2-fold).

\section{Discussion}

$\gamma \delta$ T cells are a class of unconventional T cells that connect the innate and adaptive immune systems and constitute a crucial defense against microbial agents and tumors. The evaluation of $\gamma \delta \mathrm{T}$ cells is essential whenever investigation into inflammation, autoimmunity or allergy occurs. Participation in early immunity against $M . t b$ is also a feature of $\gamma \delta$ T-cells, and the aim of the present study was to describe the optimization of a flow cytometry-based $\gamma \delta$ T-cell assay developed for the assessment of $M . t b$-specific cytolytic activity.

Macrophages, a primary host cell niche for the intracellular growth and persistence of $M . t b$, are responsible for the activation of protective immune responses (22). As the in vitro growth and expansion of primary tissue macrophages is notoriously difficult, certain cell lines are commonly used to model macrophage function. Early studies indicated that THP-1, a leukemia cell line derived from a patient with acute monocytic leukemia, exhibit primary monocyte and macrophage morphological and functional properties. They are highly plastic and homogeneous, as a consequence of a minimal degree of variability in the cell phenotype (23). PMA is a common stimulus employed to induce THP-1 differentiation. The present study demonstrated that treating THP-1 cells with $40 \mathrm{ng} / \mathrm{ml}$ PMA for $24 \mathrm{~h}$ drove cells towards full macrophage differentiation, including the expansion of the cytoplasm, a higher rate of cell adherence, increased expression of the cell surface marker CD14 and high phagocytic capacity. These results indicate that, as reported in previous studies (24-26), that PMA-treated cells may represent a valuable model with which to investigate tissue macrophages.

The phagocytic capacity of macrophages is central to their function (27). In the current study, PMA-treated THP-1 cells exhibited efficient phagocytosis of M.tb (H37Ra) and the maximal percentage of phagocytosis reached $89 \%$. By contrast, undifferentiated cells incubated with identical MOIs of bacteria exhibited only marginal internalization of bacteria. When analyzing the results based on the phagocytosis, the bacteria:cell ratio of 50:1 for $2 \mathrm{~h}$ was suitable for the subsequent preparation of target cells employed in cytotoxicity assays. THP-1 monolayers remained stable until the end of the experiments.

The traditional 'gold standard' for the determination of cytotoxicity is the ${ }^{51} \mathrm{Cr}$ release assay. However, this method is not favored clinically due to certain limitations, including 
the use of radioactive reagents. Over recent years, flow cytometry-based assays have been developed in an attempt to avoid the problems associated with the ${ }^{51} \mathrm{Cr}$-assay (28-29). Flow cytometric methods enable rapid analysis to be conducted at the single cell level and may be more convenient for routine application rather than indirectly by the release of a preloaded marker. At present, the flow cytometry-based assays employ forward and side scatter characteristics for the discrimination of different cell populations and distinction between dead and viable cells, or use differential labeling of target cells with various fluorescent dyes $(19,30)$.

In the assay described in the present study, the discrimination of targets from effectors entirely depends on the cell labeling, therefore, it is crucial to stain the target cells with a fluorescent dye that is sensitive, does not leak into target cells and does not affect the cell viability. The low cost of CFSE with a simple and rapid labeling protocol makes it a convenient dye for clinical use in laboratories, and, it is suitable for use in combination with a second fluorescent label, such as PI, to determine the target cell viability. This was therefore selected for the labeling of target cells in the current study. CFSE and PI are readily distinguished by flow cytometry using the FL1- and FL3-channels, respectively, without spectral overlap. The specific lysis was measured via the uptake of PI in the CFSE-positive target cells following incubation with effector cells.

In conclusion, the present study describes a convenient assay that is based on the direct quantitative and qualitative analysis of cell damage at a single cell level utilizing a two-color flow cytometric assay. The final format of this simple flow cytometry-based assay for the determination of the cytolytic activity of $\gamma \delta$ T lymphocytes against mycobacterium will employ rhIL-2- and $M$.tb-HAg-expanded T cells as effective $\gamma \delta$ T cells, use an MOI of 50:1 for $2 \mathrm{~h}$ in the preparation of target cells, require $8 \times 10^{4}$ target cells per sample and include the collection of 2,000 target events per sample. Flow cytometry for the determination of $\gamma \delta \mathrm{T}$ cell activity is a promising alternative to the conventional ${ }^{51} \mathrm{Cr}$ release assay. The present study may provide valuable information concerning the methods for the investigation of $\gamma \delta \mathrm{T}$ cell function, and potentially the function of other lymphocyte subsets.

\section{Acknowledgements}

The present study was supported by the Natural Science Foundation of Anhui province (grant no. 1508085QH175), the Scientific Research Innovation Team Project of Anhui Colleges and Universities (grant no. 2016-40), the University Natural Science Project of Anhui Province (grant nos. KJ2016A867 and KJ2017A229) and the National Training Programs of Innovation and Entrepreneurship for Undergraduates (grant no. 201610367010).

\section{References}

1. Zumla A, George A, Sharma V, Herbert RH; Baroness Masham of Ilton, Oxley A and Oliver M: The WHO 2014 global tuberculosis report-further to go. Lancet Glob Health 3: e10-e12, 2015.

2. Ferreira LM: Gammadelta T cells: Innately adaptive immune cells?. Int Rev Immunol 32: 223-248, 2013.
3. Born WK, Kemal Aydintug M and O'Brien RL: Diversity of $\gamma \delta$ T-cell antigens. Cell Mol Immunol 10: 13-20, 2013.

4. Baldwin CL and Telfer JC: The bovine model for elucidating the role of $\gamma \delta \mathrm{T}$ cells in controlling infectious diseases of importance to cattle and humans. Mol Immunol 66: 35-47, 2015.

5. Latha TS, Reddy MC, Durbaka PV, Rachamallu A, Pallu R and Lomada D: $\gamma \delta$ T cell-mediated immune responses in disease and therapy. Front Immunol 5: 571, 2014

6. Augustin A, Kubo RT and Sim GK: Resident pulmonary lymphocytes expressing the gamma/delta T-cell receptor. Nature 340: 239-241, 1989.

7. Pechhold K, Wesch D, Schondelmaier S and Kabelitz D: Primary activation of $\mathrm{V}$ gamma 9-expressing gamma delta $\mathrm{T}$ cells by Mycobacterium tuberculosis. Requirement for Th1-type CD4 T cell help and inhibition by IL-10. J Immunol 152: 4984-4992, 1994.

8. El Daker S, Sacchi A, Montesano C, Altieri AM, Galluccio G, Colizzi V, Martini F and Martino A: An abnormal phenotype of lung $\mathrm{V} \gamma 9 \mathrm{~V} \delta 2 \mathrm{~T}$ cells impairs their responsiveness in tuberculosis patients. Cell Immunol 282: 106-112, 2013.

9. Zheng J, Liu Y, Lau YL and Tu W: $\gamma \delta$-T cells: An unpolished sword in human anti-infection immunity. Cell Mol Immunol 10: $50-57,2013$

10. Qin G, Liu Y, Zheng J, Xiang Z, Ng IH, Malik Peiris JS, Lau YL and Tu W: Phenotypic and functional characterization of human $\gamma \delta$ T-cell subsets in response to influenza A viruses. J Infect Dis 205: 1646-1653, 2012.

11. Li H, Xiang Z, Feng T, Li J, Liu Y, Fan Y, Lu Q, Yin Z, Yu M, Shen $C$ and Tu W: Human V $\gamma 9$ V $\delta 2-T$ cells efficiently kill influenza virus-infected lung alveolar epithelial cells. Cell Mol Immunol 10: 159-164, 2013.

12. Qin G, Liu Y, Zheng J, Ng IH, Xiang Z, Lam KT, Mao H, $\mathrm{Li} \mathrm{H}$, Peiris JS, Lau YL and Tu W: Type 1 responses of human V $\gamma 9$ V82 T cells to influenza A viruses. J Virol 85: 10109-10116, 2011.

13. Wallace M, Bartz SR, Chang WL, Mackenzie DA, Pauza CD and Malkovsky M: Gamma delta T lymphocyte responses to HIV. Clin Exp Immunol 103: 177-184, 1996.

14. Mattarollo SR, Kenna T, Nieda M and Nicol AJ: Chemotherapy and zoledronate sensitize solid tumour cells to Vgamma9Vdelta2 T cell cytotoxicity. Cancer Immunol Immunother 56: 1285-1297, 2007.

15. Bonneville M, Chen ZW, Déchanet-Merville J, Eberl M, Fournié JJ, Jameson JM, Lopez RD, Massaia M and Silva-Santos B: Chicago 2014-30 years of $\gamma \delta$ T cells. Cell Immunol 296: 3-9, 2015.

16. Poccia F, Battistini L, Cipriani B, Mancino G, Martini F, Gougeon ML and Colizzi V: Phosphoantigen-reactive Vgamma9Vdelta2 $\mathrm{T}$ lymphocytes suppress in vitro human immunodeficiency virus type 1 replication by cell-released antiviral factors including CC chemokines. J Infect Dis 180: 858-861, 1999.

17. Watanabe N, Narita M, Yokoyama A, Sekiguchi A, Saito A, Tochiki N, Furukawa T, Toba K, Aizawa Y and Takahashi M: Type I IFN-mediated enhancement of anti-leukemic cytotoxicity of gammadelta $\mathrm{T}$ cells expanded from peripheral blood cells by stimulation with zoledronate. Cytotherapy 8: 118-129, 2006.

18. Somanchi SS, McCulley KJ, Somanchi A, Chan LL and Lee DA: A novel method for assessment of natural killer cell cytotoxicity using image cytometry. PLoS One 10: e0141074, 2015.

19. Jang YY, Cho D, Kim SK, Shin DJ, Park MH, Lee JJ, Shin MG, Shin JH, Suh SP and Ryang DW: An improved flow cytometry-based natural killer cytotoxicity assay involving calcein AM staining of effector cells. Ann Clin Lab Sci 42: 42-49, 2012.

20. Peng MY, Wang ZH, Yao CY, Jiang LN, Jin QL, Wang J and Li BQ: Interleukin 17-producing gamma delta T cells increased in patients with active pulmonary tuberculosis. Cell Mol Immunol 5: 203-208, 2008.

21. Fuss IJ, Kanof ME, Smith PD and Zola H: Isolation of whole mononuclear cells from peripheral blood and cord blood. Curr Protoc Immunol 7: Unit7.1, 2009.

22. Hingley-Wilson SM, Sly LM, Reiner NE and McMaster WR: The immunobiology of the mycobacterial infected macrophage. Mod Aspects Immunobiol 1: 96-101, 2000.

23. Chanput W, Mes JJ and Wichers HJ: THP-1 cell line: An in vitro cell model for immune modulation approach. Int Immunopharmacol 23: 37-45, 2014. 
24. Daigneault M, Preston JA, Marriott HM, Whyte MK and Dockrell DH: The identification of markers of macrophage differentiation in PMA-stimulated THP-1 cells and monocytederived macrophages. PLoS One 5: e8668, 2010.

25. Chanput W,Mes JJ, Savelkoul HF and Wichers HJ: Characterization of polarized THP-1 macrophages and polarizing ability of LPS and food compounds. Food Funct 4: 266-276, 2013.

26. Chanput W, Reitsma M, Kleinjans L, Mes JJ, Savelkoul HF and Wichers HJ: $\beta$-Glucans are involved in immune-modulation of THP-1 macrophages. Mol Nutr Food Res 56: 822-833, 2012.

27. Dong C, Zhao G, Zhong M, Yue Y, Wu L and Xiong S: RNA sequencing and transcriptomal analysis of human monocyte to macrophage differentiation. Gene 519: 279-287, 2013.

28. Thakur A, Zaman A, Hummel J, Jones K and Hortelano G: Single-colour flow cytometric assay to determine NK cellmediated cytotoxicity and viability against non-adherent human tumor cells. Biotechnol Lett 34: 447-453, 2012.
29. Richard J, Veillette M, Batraville LA Coutu M, Chapleau JP, Bonsignori M, Bernard N, Tremblay C, Roger M, Kaufmann DE and Finzi A: Flow cytometry-based assay to study HIV-1 gp120 specific antibody-dependent cellular cytotoxicity responses. J Virol Methods 208: 107-114, 2014.

30. Wabnitz GH, Kirchgessner H and Samstag Y: Imaging flow cytometry for multiparametric analysis of molecular mechanism involved in the cytotoxicity of human $\mathrm{CD} 8^{+} \mathrm{T}$-cells. J Cell Biochem 118: 2528-253, 2017.

(c) (i) () $\Theta$ This work is licensed under a Creative Common Attribution-NonCommercial-NoDerivatives 4.0 International (CC BY-NC-ND 4.0) License. 